\title{
Ethnic Identity and Ethnicity-Related Stress in Accompanied and Unaccompanied Adolescent Immigrants: Does the Family Work as Social Capital for Adolescent Immigrants?
}

\author{
Lars-Eric Petersen ${ }^{1}$, Ulrike Dünnbier ${ }^{1}$, Olaf Morgenroth ${ }^{2}$ \\ ${ }^{1}$ Department of Psychology, University of Halle-Wittenberg, Halle (Saale), Germany \\ ${ }^{2}$ Medical School Hamburg, Hamburg, Germany \\ Email: 1.petersen@psych.uni-halle.de
}

Received February $20^{\text {th }}, 2012$; revised March $18^{\text {th }}, 2012$; accepted April $3^{\text {rd }}, 2012$

\begin{abstract}
This study assesses the ethnic identity and ethnicity-related stress for adolescent immigrants accompanied by their families, for unaccompanied adolescent immigrants and for native (German) adolescents. Seventy adolescents completed the Ethnic Group Membership Questionnaire and the Perceived Ethnic Discrimination Questionnaire. Results show that unaccompanied adolescent immigrants $(n=20)$ report more negative private feelings about their own ethnic identity, lower beliefs about the public's regard for their ethnic group and more ethnicity-related stress in the dimensions "perceived ethnic discrimination", "stereotype confirmation concern" and "own-group conformity pressure" than accompanied adolescent immigrants $(n=25)$ and German adolescents $(n=25)$. Accompanied adolescent immigrants revealed higher scores than German adolescents only in the dimension "perceived ethnic discrimination". Results support the hypothesis derived from the theory of social capital that for the accompanied adolescent immigrants, the family works as social capital, reduces ethnicity-related stress, and promotes the development of a positive ethnic identity.
\end{abstract}

Keywords: Ethnic Identity; Ethnicity-Related Stress; Social Capital; Adolescent Immigrants

\section{Introduction}

The experience of social stress and social discrimination is part of daily life for immigrants in the Western industrialized nations (Zick, Pettigrew, \& Wagner, 2008). While the search for the reasons of this discrimination has a long tradition in psychological research (Sassenberg et al., 2007), the study of the effects of the repeated experience of stress and discriminatory behavior on the stigmatized person, however, has moved into the center of consideration only in more recent research (Contrada et al., 2001; Jasinskaja-Lahtl, Liebkind, \& Perhoniemi, 2006; Skrobanek, 2009). This study builds on this work and focuses on the experience of ethnicity-related stress and the development of an ethnic identity as part of the personal identity in young immigrants. In particular, the aim of the study is to differentiate between accompanied and unaccompanied adolescent immigrants and to focus on the family as a protective factor against stressors and social discrimination. While both groups may experience discrimination because of their social status as immigrants in a similar way, the burdens of young immigrants are different depending on whether they live with or without their parents in Germany. Young people who live with their parents in Germany may suffer under the social status as immigrants or the loss of the economic autonomy of the family. They often get into adult-oriented situations, for example as interpreters, because they have better language skills than their parents. However, the extra burdens of unaccompanied refugees are the loss of their families and relatives and the feeling of isolation, which cannot be compensated by friendships (Klingelhöfer \& Rieker, 2004).
Below we first present the concept of ethnicity by Phinney (1990, 1996a, 1996b), followed by the concepts of ethnic identity and ethnicity-related stress by Contrada et al. (2001). These approaches will help explain the specific situation of ethnic minorities. Thereafter we discuss the concept of social capital by Coleman (1988) and Portes (1998) and focus on the impact of the family on the development of ethnic identity and the experience of ethnicity-related stress by adolescents.

\section{The Concept of Ethnic Identity}

The terms ethnic identity and race are often used interchangeably to mean the same thing, but the term ethnic identity is distinct from race. Markus (2008) points out that both offer the possibility of grouping people according to physical, social or religious characteristics. However, the division into races is done preferably by others on the basis of perceived differences in appearance or behavior. However, the concept of ethnicity, Markus argues, allow people to identify with other people or groups or to be identified, based on assumed commonalties such as language, history, nationality, and region of origin, religion or physical appearance. According to this, Phinney (1996a: p. 922) defines ethnic identity as "an enduring, fundamental aspect of the self that includes a sense of membership in an ethnic group and the attitudes and feelings associated with that membership". Phinney (1996a) assumes that individuals differ in how strongly they identify with their ascribed ethnic group and how important the group identity is for their personal identity. Phinney (2000) considers the ethnic identity not as a fixed category, but as changeable by time, age and circum- 
stance.

The assumptions of Phinney (1996b) build on the theory of social identity (Tajfel \& Turner, 1986). According to this theory, the self-concept of individuals consists of a personal and a social identity. Social identity refers to a person's knowledge of membership in various social (e.g., religious, political or ethnic) groups, and the value and emotional significance the person places on social group memberships. The theory further postulates that individuals strive to achieve a positive social identity through the positive assessment of the groups to which a person belongs. Based on this assumption, Luhtanen and Crocker (1992) present the construct of collective self-esteem. Collective self-esteem is achieved through positive social comparison processes or by positive feedback from others (Luhtanen \& Crocker, 1992). Contrada et al. (2001) build on the work of Luhtanen and Crocker (1992) and propose three dimensions of ethnic identity: 1) Private feelings about one's ethnicity; 2) beliefs about the public's regard for one's ethnic group, and 3) the importance or centrality of ethnicity to identity.

In the present study, we examined our adolescent participants in a phase which Phinney (1996a) calls "ethnic identity search". At this time the adolescents have the desire to learn more about their ethnic identity (Barn, 2010). Social experiences play a major role. In this phase adolescent immigrants have more contact with people who have a different ethnic background than themselves. They are therefore also increasingly exposed to social discrimination. Hemmati et al. (1999) show that discriminatory behavior towards immigrants in Germany is a widespread phenomenon. This includes subtle acts such as avoiding contact and the omission of common forms of politeness, as well as open forms such as verbal attacks and insults and violent attacks. The consequence is that young immigrants in general should develop more negative feelings about their own ethnic identity and about the public image of their own ethnic group than the control group of German adolescents. Other results, however, can be expected for the dimension "importance or centrality of ethnicity to identity". The confrontation with majority members and their way of living should increase the reflections minority members have about their own identity and should make them more relevant. On the other hand, majority members have little reason to reflect about their ethnicity in everyday life.

Hypotheses 1a-c: Accompanied and unaccompanied adolescent immigrants should have more negative feelings about their own ethnicity (H1a) and more negative beliefs about the public regard for their own ethnic group (H1b) but a higher importance or centrality of ethnicity to identity than native German adolescents (H1c).

Studies on ethnic identity usually compare members of different ethnic groups (e.g. Contrada et al., 2001). The aim of this study is not only to compare the ethnic identity of native German adolescents and immigrant adolescents but to analyze the influence of the life situation of the immigrants. Some young people come with their parents as refugees to Germany. They usually live together with their families in shared accommodation in a confined space, but schooling and social contacts can be established with the support of the family. For these adolescent immigrants, their families can be supportive as well as problematic in the process of developing a separate identity (Raynolds, 2006; Zontini, 2010). A different situation arises for adolescent immigrants who come as unaccompanied refugees to Germany. They usually grow up in youth welfare institutions or in special facilities for unaccompanied minor refugees. In the case of them being 16 or older, placement in a shared accommodation is also possible. For these youths, the family is not available for them to acquire information about their own ethnic identity. Information about their own ethnic group will be acquired in the form of - often negative - social reactions by the majority. This should lead to more negative feelings and the perception of more negative beliefs about their ethnic group by the public. Some studies already expressed concerns about potential risk factors which may lead unaccompanied adolescent immigrants to internalize racism and be ill-equipped to develop a positive ethnic identity (Barn, 2010; Robinson, 2000). Moreover, beliefs about one's ethnicity should not be so detailed and extensive in contrast to the beliefs of unaccompanied adolescent immigrants, for whom social reactions by the majority should lead to a lesser importance of their own ethnicity for their own identity.

Hypotheses 2a-c: Accompanied adolescent immigrants should have more positive feelings about their own ethnicity (H2a), more positive beliefs about the public regard for their own ethnic group (H2b), and a higher importance or centrality of ethnicity to identity than unaccompanied adolescent immigrants (H2c).

\section{Ethnicity-Related Stress}

Another aspect of ethnicity is the experiences that are made in connection with the status as a minority. These were examined in the form of ethnicity-related stress by Contrada et al. (2001). They define ethnicity-related stress as "the outcome of a person-situation interaction in which perception of features of the social environment, in the light of knowledge of one's ethnicity, leads either to the anticipation of psychological or physical harm, or to the belief that such harm has already occurred" (Contrada et al., 2001: p. 1777). Three forms of ethnicityrelated stress were proposed: 1) ethnic discrimination; 2) stereotype confirmation concern and 3) own-group conformity pressure.

Contrada et al. (2001) defined ethnic discrimination as an unfair treatment attributed to one's ethnicity. Ethnic discrimination has been studied most often as a discrimination that emanates from members of a (usually white) majority against minorities. Most research was conducted in the United States. Various methods, such as interviews, surveys, content analyses, and standardized questionnaires were used (e.g. Feagin \& Sikes, 1994; Lykes, 1983; Landrine \& Klonoff, 1996). The results have shown that discrimination is a common occurrence in the United States and that African Americans are particularly affected (Landrine \& Klonoff, 1996; McNeilly et al., 1996). African Americans reported both very aggressive forms, such as physical assaults and threats, as well as subtle forms of discrimination, such as the avoidance of contact. Instruments to measure perceived discrimination, such as the Schedule of Racist Events (SRE; Landrine \& Klonoff, 1996) and the Perceived Racism Scale (PRS; McNeilly et al., 1996), assess the frequency of racist experiences. However, these have been developed specifically for African American people. Contrada et al. (2001) developed a questionnaire which measures different types of ethnic discrimination and is appropriate for use with all ethnic groups.

The concept of stereotype confirmation concern is based on findings that indicate that individuals of stigmatized groups are aware of the stereotypes about their group and fear being 
evaluated according to these stereotypes or to confirm them by their own behavior. Steele and Aronson (1995) describe this apprehension as stereotype threat. They assume that stereotype threat is an acute social psychological state or event, and primarily study the effects of direct confrontation with stereotypes (Aronson, Quinn, \& Spencer, 1998). Contrada et al. (2001) conceptualize stereotype confirmation concern as a relatively enduring or recurring experience of stereotype threat. It is therefore a persistent experience of uncertainty and apprehendsion about confirming a stereotype about the group to which one belongs. In addition, Contrada et al. (2001) assume that all ethnic groups have these fears. Stereotypes of ethnic groups are multifaceted. Therefore, it is possible that many people fear confirming multiple stereotypes. These assumptions were taken into account by Contrada et al. (2001) in the construction of the scale to measure stereotype confirmation. The scale contains items that refer to several behavioral areas potentially relevant to various ethnic stereotypes.

The previously described components of ethnicity-related stress refer to phenomena that arise from the relationship between majority and minority. The third facet of ethnicity-related stress, however, has its origins within the group. Based on the observation of Fordham and Ogbu (1986) that some African Americans accuse other African American students of "acting white" when they apply themselves to academic work, Contrada et al. (2001) developed the concept of own-group conformity pressure. They define this type of ethnicity-related stress as "the experience of feeling pressured or constrained by expectations from members of one's own ethnic group that specify what is considered appropriate or inappropriate behavior for that group" (Contrada et al., 2001: p. 1779). Responsible for this experience are either characteristics of the person or the social environment. The personal aspects include their own ethnicity and factors influencing the perception of group norms and expectations. Among the social aspects, overt sanctions for violating ethnic group norms and more subtle reminders of how to behave are important.

\section{The Family as a Buffer for Ethnicity-Related Stress}

Good family relationships have a positive effect on coping with stressors (DeGarmo \& Martinez, 2006; Fuligni \& Yoshikawa, 2003). Slonim-Nevo, Mirsky, Rubinstein, \& Nauck (2009) showed that family relations were significantly related to adjustment to the host country in migrants in Israel and Germany. The authors report that functioning relationships within the family have a positive impact on the prevention of stress and the development of self-esteem.

Slonim et al. (2009) employ the theory of social capital (Coleman, 1988; Portes, 1998) to explain their results. Coleman (1988) describes social capital as a resource for action. Unlike financial capital or human capital, social capital is not tied to a person but to the structure of relationships between people. The family constitutes a crucial aspect of social capital. Furthermore, Coleman defines social capital functionally: "It is not a single entity but a variety of different entities, with two elements in common: they all consist of some aspect of social structures, and they facilitate certain action of actors-whether persons or corporate actors - within the structure. Like other forms of capital, social capital is productive, making possible the achievement of certain ends that in its absence would not be possible" (Coleman, 1988, p. 98). In this sense capital is anything that facili- tates individual or collective action, generated by networks of relationships.

Portes (1998) defines social capital as "the ability of actors to secure benefits by virtue of membership in social networks or other social structures" (p. 6). He also identifies three main functions that need to be distinguished. Social capital is a source of social control, family support and benefits, which result from extended family networks. The social capital of the family is seen in the relationship between children and parents. There is a growing interest in social capital and young people (Barn, 2010; Weller, 2010), especially in immigrant families (Zontini, 2010). DeGarmo and Martinez (2006) find in a study with Latino youth that social support buffered effects of discrimination on academic well-being, and parental support was most predictive of greater academic well-being. Therefore, good family relations should help to reduce fears and uncertainties, such as the fear of confirming stereotypes through their own behavior. This means that accompanied adolescent immigrants should feel less ethnicity-related stress and should be less afraid to confirm stereotypes than unaccompanied adolescent immigrants. Further, accompanied adolescent immigrants should in ambigious situations interpret actions and statements of other people less likely as discriminating than accompanied adolescent immigrants. However, due to the previously reported findings of everyday discrimination of immigrants in Germany (Hemmati et al., 1999), both groups should perceive more ethnic discrimination and should have more fear of confirming to stereotypes than the adolescents of the control group.

Hypothesis 3: Accompanied and unaccompanied adolescent immigrants should perceive more ethnic discrimination than native German adolescents.

Hypothesis 4: Unaccompanied adolescent immigrants should perceive more ethnic discrimination than accompanied adolescent immigrants.

Hypothesis 5: Accompanied and unaccompanied adolescent immigrants should have more stereotype confirmation concern than native German adolescents.

Hypothesis 6: Unaccompanied adolescent immigrants should have more stereotype confirmation concern than accompanied adolescent immigrants.

Portes (1998), however, has also pointed to the negative consequences that are associated with social capital. He emphasizes here a stressor, which Contrada et al. (2001) also includes in their concept of ethnicity-related stress: the own-group conformity pressure. It could be assumed that living with parents and closer contact with members of their own ethnic group make young people more likely to conform to the standards and values of their own ethnic group in order to avoid sanctions. Thus, the pressure to behave in a certain way should lead to higher scores on the dimension own-group conformity pressure for adolescent immigrants who live together with their families than for young people from ethnic minorities, who do not live with their parents.

Hypothesis 7: Accompanied adolescent immigrants should perceive more own-group conformity pressure than unaccompanied adolescent immigrants.

\section{Method}

\section{Sample}

Seventy adolescents participated in the study. Thirty-eight of the participants were women and thirty-two were men. Partici- 
pants were between 13 and 20 years old $(M=17.21, S D=1.70)$. The participants were assigned to the three groups in the following manner: 25 participants who specified German as native language and cultural group formed the control group. 25 participants who specified German not as their cultural group or mother tongue and indicated living with their families formed the group of accompanied immigrants. Adolescents who currently live as unaccompanied minor refugees in Germany formed the group of unaccompanied adolescent immigrants. The group of unaccompanied immigrants consists of 20 adolescents. The origin of the immigrants was Asia (40\%), Russia (24.4\%), Eastern Europe (20\%) and Africa (15.6\%).

\section{Procedure}

The participants were recruited in cooperation with teachers from different schools in the state of Saxony-Anhalt and in cooperation with organizations which support immigrants. The participants were reassured of anonymity and confidentiality, and provided with adequate information to help them formulate informed consent to participate in the study. All participants were informed of their right to withdraw from the study or to refuse to answer any questions they deemed to be too sensitive. Immigrants also received help when they had difficulties with the German language. All participants were given a questionnaire. They were first asked to indicate their mother tongue and cultural group. In addition, demographic variables of age, gender, school and grade were collected. With a total of 58 items, the following constructs were measured:

Ethnic identity. The Ethnic Group Membership Questionnaire (EGMQ) by Contrada et al. (2001) was used. In the original version this questionnaire consists of 12 items, with four items for each of the three dimensions 1) private feelings; 2) public regard and 3) identity centrality. We translated the EGMQ into German and shortened the questionnaire by 2 items whose wording and meaning in German is uncommon. The dimension "private feelings" was measured with 4 items (e.g., "I often regret that I belong to the ethnic group I do", reverse scored), the scale mean was $M=4.57(S D=1.05)$, and Cronbach's alpha was .71 . The dimension "identity centrality" was also measured with 4 items (e.g., "The ethnic group that I belong to is an important reflection of who I am"), the scale mean was $M=3.59(S D=1.04)$, and Chronbach's alpha was .64 . Finally, the dimension "public regard" was measured with two items (e.g., "Overall, my ethnic group is viewed positively by others"), the scale mean was $M=4.08(S D=1.20)$, and Chronbach's alpha was .61. All 10 items were scored on 6-point scales ranging from 1 (strongly disagree) to 6 (strongly agree).

Perceived ethnic discrimination. This form of ethnicity-related stress was measured with the Perceived Ethnic Discrimination Questionnaire (PEDQ) by Contrada et al. (2001). The questionnaire was translated into German and adapted to the characteristics of an adolescent sample. In the original version of the PEDQ of Contrada et al. the authors distinguish seven forms of discrimination, which are measured by 22 items. The seven forms are 1) verbal rejection (e.g., "Offensive ethnic comments aimed directly at you"); 2) avoidance (e.g., "Others avoided you because of your ethnicity"); 3) exclusion (e.g., "You were denied access to a public facility because of your ethnicity"); 4) denial of equal treatment (e.g., "You received unfair treatment from school officials because of your ethnicity"); 5) disvaluing action (e.g., "Others had implied or sug- gested that you must be violent or dangerous because of your ethnicity"); 6) threat of aggression (e.g., "Others threatened to hurt you because of your ethnicity"); 7) aggression (e.g., "Others physically hurt or intended to hurt you because of your ethnicity"). In the present study we added 2 items on perceived discrimination in school, such as, "How many times have you been abused by fellow students because of your ethnicity?" and "How often did you feel threatened in school because of your ethnicity?" We further added the following 3 items that relate to the dimension "denial of equal treatment": "How often have you not gone into a nightclub or bar because of your ethnicity?", "How many times were you treated unfairly by police officers because of your ethnicity?" and "How often were you treated unfairly by authorities and agencies because of your ethnicity?" Item 11 of the PEDQ of Contrada et al. (2001), which refers to work situations, has been omitted. In addition, three other items were omitted (items 1, 12, 22 of the original questionnaire), because they do not reflect the situation of young people in Germany (e.g. nonverbal harassment like being given "the finger") or appeared too difficult (e.g., "How often do others have low expectations of you?"). With the added items, this questionnaire part consists of 23 items. In response to each of these items, participants were instructed to use a 6-point scale ranging from 1 (never) to 6 (very often) to indicate how often over the past 3 months each form of discrimination had been directed at them. The scale mean was $M=1.77(S D=.82)$, and Chronbach's alpha was .95.

Stereotype conformation concern. Concerns of confirming stereotypes about the own ethnic group were measured with the Stereotype Confirmation Scale (SCCS) by Contrada et al. (2001). The original scale consists of 11 items. For this study, the SCCS was translated into German and adapted to the situation of young people in Germany. The items 4, 5, 10 and 11 of the original scale were removed because they seemed neither appropriate nor relevant to the situation of young people in Germany (e.g., "How often have you been concerned that in doing certain household tasks you might appear to confirm a stereotype of your ethnic group?"). The scale used in this study to measure concerns about confirming stereotypes includes 7 items. Participants were asked to use a 6-point scale ranging from 1 (never) to 6 (always) to indicate how often over the past 3 months they have been "concerned that by ___ [they] might appear to be confirming a stereotype about [their] ethnic group". Specific behaviors mentioned in individual items include dressing a certain way, talking in certain ways or eating. The scale mean was $M=1.89(S D=.81)$, and Chronbach's alpha was .79.

Own-Group Conformity Pressure. The conformity pressure of the own-group was measured with the Own-Group Conformity Pressure Scale (OGCPS) by Contrada et al. (2001). The original scale consists of 16 items. In the present study the items $13,14,15$ and 16 were omitted because they do not reflect the situation of young people in Germany. For the adopted 12 items the participants were asked to use a 6-point scale ranging from 1 (not at all pressured) to 6 (quite a bit pressured) to indicate, for the past 3 months, "To what degree [they] have felt pressured by members of [their] ethnic group to Individual items referred to social interactions with their own and other group members, interests and hobbies, music preferences and style of dress. The scale mean was $M=1.63$ ( $S D$ $=.62$ ), and Chronbach's alpha was .83 . 


\section{Results}

\section{Ethnic Identity}

Mean ratings of the variables "Private feelings", "Public regard" and "Identity centrality" for the German adolescents of the control group, for accompanied adolescent immigrants and for unaccompanied adolescent immigrants are displayed in Figure 1.

Private feelings. A univariate ANOVA revealed significant differences between conditions, $F(2,67)=16.21, p<.01, \eta^{2}$ $=.33$. Planned comparisons (t-tests) to test H1a and $\mathrm{H} 2 \mathrm{a}$ showed that unaccompanied adolescent immigrants $(M=3.66$, $S D=.92)$ reported significantly more negative feelings than German adolescents $(M=4.73, S D=.91, t(43)=3.67, p<.001)$ and accompanied adolescent immigrants $(M=5.13, S D=.68$, $t(43)=5,73, p<.001)$. All other planned comparisons were not significant. This means that adolescent immigrants do not generally have more negative feelings about their own ethnicity than German adolescents, thus H1a is only supported for unaccompanied adolescent immigrants but not for accompanied adolescent immigrants. Further, results show that accompanied adolescent immigrants have more positive feelings about their ethnicity than unaccompanied adolescent immigrants. Thus, we found support for $\mathrm{H} 2 \mathrm{a}$.

Public regard. A univariate ANOVA revealed significant differences between the three groups, $F(2,67)=4.54, p<.05$, $\eta^{2}=.12$. Unaccompanied adolescent immigrants $(M=3.45, S D$ $=1.16$ ) rated the public regard of their group significantly lower than German adolescents $(M=4.46, S D=1.07, t(43)=$ $3.04, p<.05)$ and accompanied adolescent immigrants $(M=$ $4.20, S D=1.20, t(43)=2.11, p<.05)$. All other planned comparisons were not significant. These results show that adolescent immigrants do not generally rate the public regard of their group lower than German adolescents, thus H1b is only supported for unaccompanied adolescents immigrants but not for accompanied adolescent immigrants. $\mathrm{H} 2 \mathrm{~b}$ is supported by the data: Accompanied adolescent immigrants reported more positive beliefs about the public regard for their own ethnic group than unaccompanied adolescent immigrants.

Identity centrality. A univariate ANOVA showed that German adolescents $(M=3.32, S D=1.05)$, accompanied adolescent immigrants $(M=3.90, S D=1.07)$ and unaccompanied adolescent immigrants $(M=3.53, S D=.90)$ do not differ in the rating of the importance or centrality of ethnicity for their identity, $F(2,67)=2.09, p$ ns.

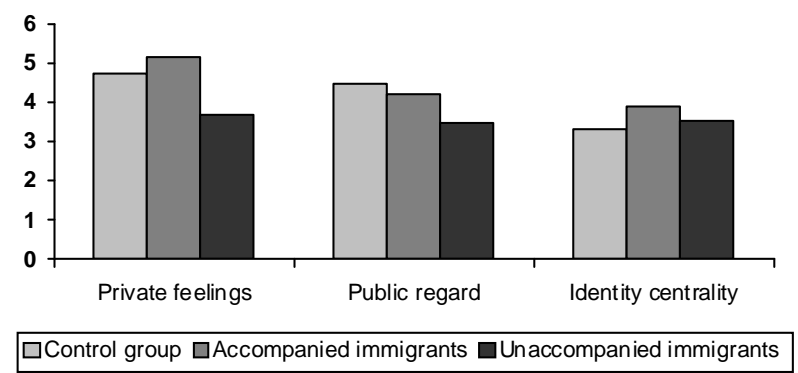

\section{Figure 1.}

Mean ratings of the variables "Private feelings about one's ethnicity," "Beliefs about the public's regard for one's ethnic group" and "Importance or centrality of ethnicity to identity" for the German adolescents of the control group, for accompanied adolescent immigrants and for unaccompanied adolescent immigrants.

\section{Ethnicity-Related Stress}

Mean ratings of the variables "Perceived ethnic discrimination," "Stereotype confirmation concern" and "Own-group conformity pressure" for the German adolescents of the control group, for accompanied adolescent immigrants and for unaccompanied adolescent immigrants are displayed in Figure 2.

Perceived ethnic discrimination. A univariate ANOVA revealed significant differences between conditions, $F(2,67)=$ 17.80, $p<.001, \eta^{2}=.35$. Planned comparisons to test $\mathrm{H} 3$ showed that accompanied adolescent immigrants $(M=1.80, S D$ $=.77, t(48)=3.56, p<.001)$ as well as unaccompanied adolescent immigrants $(M=2.42, S D=86, t(43)=6.55, p<.001)$ reported a significantly higher perceived ethnic discrimination than German adolescents $(M=1.21, S D=.30)$. Thus, H3 was supported. Furthermore, in support of H4, unaccompanied adolescent immigrants perceive significantly more ethnic discrimination $(M=2.41)$ than accompanied adolescent immigrants $(M=1.80, t(43)=2.52, p<.05)$.

Stereotype confirmation concern. A univariate ANOVA revealed significant differences between conditions, $F(2,67)=$ 3.34, $p<.05, \eta^{2}=.09$. Planned comparisons displayed that while on the one hand unaccompanied adolescent immigrants $(M=2.26, S D=.86)$ show more stereotype confirmation concern than German adolescents $(M=1.65, S D=.68, t(43)=$ $2.60, p<.05)$, on the other hand the stereotype confirmation concern reported by accompanied adolescent immigrants and German adolescents do not differ $(M=1.83, S D=.82$ vs $M=$ $1.65, S D=.68, t(48)=.80, p$ ns.). Therefore, adolescent immigrants do not generally show a greater fear of confirming to stereotypes than German adolescents. Thus, H5 was not supported. However, we found some support for H6: Unaccompanied adolescent immigrants $(M=2.26)$ reported tendencially more stereotype confirmation concern than accompanied adolescent immigrants $(M=1.83, t(43)=1.70, p<.10)$.

Own-group conformity pressure. A univariate ANOVA revealed significant differences between conditions, $F(2,67)=$ 4.04, $p<.05, \eta^{2}=.11$. Planned comparisons displayed that unaccompanied adolescent immigrants tendencially perceived more own-group conformity pressure $(M=1.94, S D=.73)$ than accompanied adolescent immigrants $(M=1.56, S D=66, t(43)$ $=1.83, p<.10)$ and significantly more own group conformity pressure than German adolescents $(M=1.44, S D=.37, t(43)=$ $2.94, p<.01)$. Thus, the results do not confirm H7, that living with parents and having closer contact with members of their own ethnic group leads accompanied adolescent immigrants to

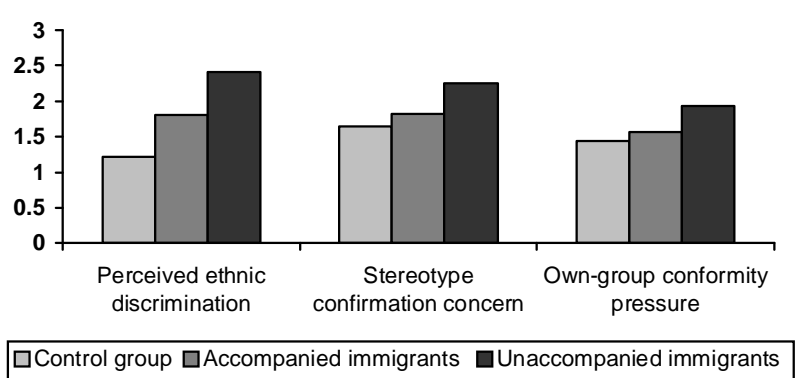

Figure 2.

Mean ratings of the variables "Perceived ethnic discrimination," "Stereotype confirmation concern" and "Own-group conformity pressure" for the German adolescents of the control group, for accompanied adolescent immigrants and for unaccompanied adolescent immigrants. 
feel more conformity pressure than unaccompanied adolescent immigrants. On the contrary, unaccompanied immigrants report the highest values in the dimension of own-group conformity pressure.

\section{Discussion}

This study had two main goals. Firstly, the development of ethnic identity and ethnicity-related stress among adolescent immigrants in Germany should be compared with German adolescents. Second, the impact of living with the family on the development of ethnic identity and the experience of ethnicity-related stress should be studied. Therefore we differentiated between accompanied and unaccompanied adolescent immigrants.

\section{Ethnic Identity}

When comparing the groups, only two significant results were found. These related to the dimensions of private feelings about one's ethnic identity and the beliefs about the public's regard for one's ethnic group. Here unaccompanied adolescent immigrants revealed significantly more negative feelings and reported lower beliefs about the public regard of their ethnic group than accompanied adolescent immigrants and German youths. No differences on these dimensions were found for accompanied adolescent immigrants and German youths. It must also be noted here that the values for all three groups - and thus also for unaccompanied young immigrants - were high in absolute magnitude. Furthermore, contrary to the hypotheses, the importance or centrality of ethnicity to identity was not higher for the two immigrant groups than for the German group.

The results of this study are therefore interesting in two ways. Firstly, the present study shows that there are, if any, only minor differences between adolescent immigrants and German adolescents regarding the positivity and the importance of their own ethnic identity. What the self-esteem theory proposes (Petersen, Stahlberg, \& Dauenheimer, 2000) for personal identity, what the social identity theory (Tajfel \& Turner, 1986) postulated for the social identity and what was demonstrated in a large number of studies (Baumeister, 1988) seems to be true for the ethnic identity, too: People have a strong desire to achieve a positive identity, and they often succeed in building a positive identity despite unfavorable conditions. Although adolescent immigrants experience increased discrimination due to their ethnicity - as also shown in this study - they succeed overall in developing positive feelings concerning their ethnicity and in generating positive beliefs about the public's regard for their ethnic group. It is left to subsequent research to find out if people, regarding the development of their own ethnicity, use similar positivity biases to achieve a positive personal or social identity (Crocker \& Major, 1989), or whether they employ specific strategies in the field of ethnic identity.

Second, this study also indicates that the family may have some influence on the perception of one's own ethnic group. In her three-phase model of the development of ethnic identity, Phinney describes that in the second phase, young people feel a strong desire to learn about their group (Phinney, 1996a). Various information sources may explain the difference in terms of public regard and personal feelings about their ethnicity, which was found between accompanied and unaccompanied adolescent immigrants. Thus, accompanied adolescent immigrants have the possibility to compare and discuss their negative experiences with other members of their group because of their group membership. Accompanied adolescent immigrants should also receive positive and appropriate ethnic socialization messages from their parents, leading to a good understanding of ethnic identity and to coping strategies to confront discrimination behavior (Stevenson, 1995). Living with parents could thus help young immigrants, despite the experience of ethnic discrimination, to develop a positive ethnic identity. Our results are also consistent with some British studies who shows that accompanied adolescent immigrants do not generally experience problems and concerns about their ethnic identity (Barn, Andrew, \& Mantovani, 2005; Reynolds, 2006).

Unaccompanied refugees, however, have problems in this phase of their own ethnic identity development getting information about their own ethnic group from group members. Due to the fact that they often live in collective accommodations together with other young people who also possess no established ethnic identity or belong to other ethnic groups, they have difficulties accessing adult members of their own ethnic group. This could mean that they are mainly dependent on information outside their ethnic group. This lack of opportunity to compare experiences with discrimination could be used as one explanation why unaccompanied adolescent immigrant have more negative feelings about their own ethnic group and lower beliefs about the public regard for their own group compared to accompanied adolescent immigrants.

\section{Ethnicity-Related Stress}

Contrary to the results concerning the ethnic identity, significant differences between groups occur for the magnitude of ethnicity-related stress in all three dimensions. Both accompanied and unaccompanied adolescent immigrants reported more perceived ethnic discrimination in everyday life, such as verbal rejections, exclusions, denial of equal treatment and disvaluing actions, than German adolescents. Unaccompanied immigrants reported significantly more of these experiences than accompanied adolescent immigrants. Furthermore, unaccompanied immigrants also reported a significantly greater anxiety to confirm stereotypes with their own behavior than accompanied adolescent immigrant and German adolescents. Finally, contrary to our hypothesis, unaccompanied adolescent immigrants reported an increased own-group conformity pressure, for example in interactions with own and other group members, interests and style of dress.

The differences in experienced ethnicity-related stress between accompanied and unaccompanied adolescent immigrants support the assumption that the family can act as a protective factor for different stressors that are associated with one's own ethnicity. This is consistent with previous studies (DeGarmo \& Martinez, 2006; Slonim-Nevo et al., 2009), which also show that the family works as social capital and has a positive impact on the prevention of stress. The assumption of Porter (1998) that living with parents and having closer contact with members of their own ethnic group leads young people to the experience of more own-group conformity pressure was not supported by the results of this study. Rather, it seems that accompanied adolescent immigrants have benefits from living together with their families without having costs such as an increased pressure to conform with the standards and values of the own ethnic group. In contrast, unaccompanied adolescent immigrants seem 
to experience conformity pressure in contact with people of their ethnic group who do not belong to their families and give this conformity pressure a greater importance than accompanied immigrants. Accompanied adolescent immigrant could therefore benefit in all dimensions of ethnicity-related stress from living together with their families.

\section{Limitations and Future Directions}

In the present study significant differences between accompanied and unaccompanied adolescent immigrants were shown concerning private feelings about their ethnicity and ethnicityrelated stress. Our explanation for these differences builds on family support and benefits, which result from extended family networks. Subsequent studies could support this explanation by measuring the quality of family relationships as well as the extent of the family network and by showing that these factors moderate the development of the ethnic identity and the perception of ethnic-related stress.

An alternative explanation for the reported differences between accompanied and unaccompanied adolescent immigrants could be derived from potentially different life stories of the members in these two groups. It can be assumed that unaccompanied young immigrants have experienced more dramatic events in their flight (including the separation from their families) than accompanied immigrants. These experiences, which met unaccompanied adolescent immigrants on their way to Germany, probably weakened their mental state and increased their vulnerability to stressors in general. The necessary data for an evaluation of the described alternative explanation were not included in this study for several reasons. First, it would have meant the inclusion of additional items in the questionnaire. This would have been, given the limited language skills of the immigrant participants and the already extensive questionnaire, an undue additional workload for the participants. On the other hand-which was a much more important reason-asking questions about events during the flight and separation from their parents contains the danger of reactivating of existent traumata. Information about such events should be obtained only if the investigators have good and lasting relationships with the study participants and could provide therapeutic options. This was not the case in the present study. Subsequent studies could benefit from such opportunities.

\section{Conclusions}

A successful integration of immigrants is one of the central social and political issues of our times (Deaux, 2000; Bürgelt, Morgan, \& Pernice, 2008). Ethnicity-related stress and ethnic discrimination can jeopardize this process of integration and the development of a positive ethnic identity. This should be particularly important during adolescence when ethnic identity becomes an important factor for developing a positive personal identity for young immigrants (Barn, 2010; Schmitt, Rodermund, \& Silbereisen, 2008). The present study shows that unaccompanied adolescent immigrants experience more ethnicity-related stress in the form of perceived ethnic discrimination, stereotype confirmation concern and own-group conformity pressure than accompanied adolescents immigrants and native adolescents. Adolescent immigrants who live together with their families, however, only report more perceived discrimination in comparison with German adolescents. Unaccompanied adolescent immigrants also report more negative feelings regarding their own ethnic identity compared to accompanied adolescent immigrants, while accompanied young immigrants have just as positive feelings concerning their ethnic identity as German adolescents. Therefore the results support the hypothesis derived from the theory of social capital (Coleman, 1988; Portes, 1998) that for accompanied adolescent immigrants the family works as social capital, reduces ethnicity-related stress and promotes the development of a positive ethnic identity. Subsequent studies could further support this conclusion by showing that the quality of family relationships has a positive impact on the development of the ethnic identity and dealing with ethnicity-related stress.

\section{REFERENCES}

Aronson, J., Quinn, D. M., \& Spencer, S. J. (1998). Stereotype threat and the academic underperformance of minorities and women. In J. K. Swim, \& C. Stangor (Eds.), Prejudice: The target's perspective (pp. 83-103). San Diego, CA: Academic Press.

Barn, R. (2010). Care leavers and social capital: Understanding and negotiating racial and ethnic identity. Ethnic and Racial Studies, 33, 832-850. doi:10.1080/01419870903318896

Barn, R., Andrew, L., \& Mantovani, N, (2005). Life after care: A study of the experience of young people from different ethnic groups. York: Joseph Rowntree Foundation

Baumeister, R. F. (1998). The self. In D. T. Gilbert, S. T. Fiske, \& G. Lindzey (Eds.), The handbook of social psychology (4th ed., Vol. 1, pp. 680-740). New York, NY: McGraw-Hill.

Bürgelt, P. T., Morgan, M., \& Pernice, R. (2008). Staying or returning: Pre-migration influences on the migration process of German migrants to New Zealand. Journal of Community and Applied Social Psychology, 18, 282-298. doi:10.1002/casp.924

Coleman, J. S. (1988). Social capital in the creation of human capital. American Journal of Sociology, 94, 95-121. doi:10.1086/228943

Contrada, R. J., Ashmore, R. D., Gary, M. L., Coups E., Egeth, J. D., Sewell, A., Ewell, K., Goyal, T. M., \& Chasse, V. (2001). Measures of ethnicity-related stress: Psychometric properties, ethnic group differences, and associations with well-being. Journal of Applied Social Psychology, 31, 1775-1820. doi:10.1111/j.1559-1816.2001.tb00205.x

Crocker, J., \& Major, B. (1989). Social stigma and self-esteem: The self-protective properties of stigma. Psychological Review, 96, 608639. doi:10.1037/0033-295X.96.4.608

De Garmo, D. S., \& Martinez, C. R. (2006). A culturally informed model of academic well-being for Latino youth: The importance of discriminatory experience and social support. Family Relations, 55, 267-278. doi:10.1111/j.1741-3729.2006.00401.x

Deaux, K. (2000). Surveying the landscape of immigration: Social psychological perspectives. Journal of Community and Applied Social Psychology, 10, 421-431. doi:10.1002/1099-1298(200009/10)10:5<421::AID-CASP598>3.0.C $\mathrm{O} ; 2-\mathrm{Y}$

Feagin, J. R., \& Sikes, M. P. (1994). Living with racism: The black middle-class experience. Boston: Beacon.

Fordham, S., \& Ogbu, J. U. (1986). Black students' school success: Coping with the "burden of acting white". Urban Review, 18, 176206. doi:10.1007/BF01112192

Fuligni, A. J., \& Yoshikawa, H. (2003). Socioeconomic resources, parenting, and child development among immigrant families. In M. Bornstein, \& R. Bradley (Eds.), Socioeconomic status, parenting, and child development (pp. 107-124). Mahwah, NJ: Lawrence Erlbaum.

Hemmati, M., Wintermantel, M., \& Paul, M. (1999). What are the impacts of xenophobic events on foreigners? Empirical studies of cognitive, emotional and behavioural consequences. In R. Dollase et al. (Eds.), Political psychology of xenophobia: Victims-actors-collaborators. München: Juventa.

Jasinskaja, I., Liebkind, K., \& Perhoniemi, R. (2006). Perceived dis- 
crimination and well-being: A victim study of different immigrant groups. Journal of Community and Applied Social Psychology, 16, 267-284. doi: $10.1002 /$ casp.865

Klingelhöfer, S., \& Rieker, P. (2004). Young immigrants in Germany. Jugend Beruf Gesellschaft: Zeitschrift für Jugendsozialarbeit, 55, 100-108.

Landrine, H., \& Klonoff, E. A. (1996). The schedule of racist events: A measure of racial discrimination and a study of its negative physical and mental health consequences. Journal of Black Psychology, 22, 144-168. doi:10.1177/00957984960222002

Luhtanen, R., \& Crocker, J. (1992). A collective self-esteem scale: Self-evaluation one's social identity. Personality and Social Psychology Bulletin, 18, 302-318. doi:10.1177/0146167292183006

Lykes, M. B. (1983). Discrimination and coping in the lives of black woman: Analyses of oral history data. Journal of Social Issues, 39, 79-100. doi:10.1111/j.1540-4560.1983.tb00157.x

Markus, H. R. (2008). Pride, prejudice, and ambivalence: Toward a unified theory of race and ethnicity. American Psychologist, 63, 651670. doi:10.1037/0003-066X.63.8.651

McNeilly, M. D., Anderson, N. B., Armstead, C. A., Clark, R., Corbett, M., Robinson, E. L., Pieper, C. F., \& Lepisto, E. M. (1996). The perceived racism scale: A multidimensional assessment of the experiences of White racism among African Americans. Ethnicity and Disease, 6, 154-166.

Phinney, J. S. (1990). Ethnic identity in adolescents and adults: A review of research. Psychological Bulletin, 108, 499-514. doi:10.1037/0033-2909.108.3.499

Phinney, J. S. (1996a). When we talk about American ethnic groups, what do we mean? American Psychologist, 51, 918-928. doi:10.1037/0003-066X.51.9.918

Phinney, J. S. (1996b). Understanding ethnic diversity: The role of ethnic identity. American Behavioral Scientist, 40, 143-152. doi:10.1177/0002764296040002005

Phinney, J. S. (2000). Ethnic identity. In A. Kazdin, (Ed.), Encyclopedia of psychology, (Vol. 3, pp. 255-259). Washington DC: Psychological Association

Portes, A. (1998). Social capital: Its origins and applications in modern sociology. Annual Review of Sociology, 24, 1-24. doi:10.1146/annurev.soc.24.1.1

Reynolds, T. (2006). Caribbean families, social capital and young people's diasporic identities. Ethnic and Racial Studies, 29, 1087-1103. doi:10.1080/01419870600960362

Robinson, L. (2000). Racial identity attitudes and self-esteem of black adolescents in residential care: An exploratory study. British Journal of Social Work, 30, 3-24. doi:10.1093/bjsw/30.1.3

Sassenberg, K., Fehr, J., Hansen, N., Matschke, C., \& Woltin, K. A. (2007). A social-psychological analysis on how to reduce the social discrimination of migrants. Zeitschrift für Sozialpsychologie, 38, 239-249. doi:10.1024/0044-3514.38.4.239

Schmitt-Rodermund, E., \& Silbereisen, R. K. (2008). Well-adapted adolescent ethnic German immigrants in spite of adversity: The protective effects of human, social, and financial capital. European Journal of Developmental Psychology, 5, 186-209.

doi:10.1080/17405620701557290

Skrobanek, J. (2009). Perceived discrimination, ethnic identity and the (re-) ethnicisation of youth with a Turkish ethnic background in Germany. Journal of Ethnic and Migration Studies, 35, 535-554. doi:10.1080/13691830902765020

Slonim-Nevo, V., Mirsky, J., Rubinstein, L., \& Nauck, B. (2009). The impact of familial and environmental factors on the adjustment of immigrants: A longitudinal study. Journal of Family Issues, 30, 92123. doi: $10.1177 / 0192513 \mathrm{X} 08324575$

Steele, C. M., \& Aronson, J. (1995). Stereotype threat and the intellectual test performance of African Americans. Journal of Personality and Social Psychology, 69, 797-811. doi:10.1037/0022-3514.69.5.797

Stevenson, H. (1995). Relationship of adolescent perceptions of racial socialization to racial identity. Journal of Black Psychology, 21, 4970. doi: $10.1177 / 00957984950211005$

Tajfel, H., \& Turner, J. C. (1986). The social identity theory of intergroup behaviour. In S. Worchel, \& W. G. Austin (Eds.), Psychology of intergroup relations (pp. 7-24). Chicago: Nelson-Hall.

Weller, S. (2010). Young people's social capital: Complex identities, dynamic networks. Ethnic and Racial Studies, 33, 872-888. doi: $10.1080 / 01419870903254653$

Zick, A., Pettigrew, T. F., \& Wagner, U. (2008). Ethnic prejudice and discrimination in Europe. Journal of Social Issues, 64, 233-251. doi: $10.1111 / \mathrm{j} .1540-4560.2008 .00559 . \mathrm{x}$

Zontini, E. (2010). Enabling and constraining aspects of social capital in migrant families: Ethnicity, gender and generation. Ethnic and Racial Studies, 33, 816-831. doi:10.1080/01419870903254661 